\title{
Energy Characteristics of the Marmara Sea Water Circulation in 2008
}

\author{
S. G. Demyshev, S. V. Dovgaya*, M. V. Shokurov \\ Marine Hydrophysical Institute of RAS, Sevastopol, Russian Federation \\ * dovgayasvetlana0309@yandex.ru
}

Purpose. The main objectives of the study consisted in analyzing the Marmara Sea energy and in identifying the basic reasons for formation of its circulation features in 2008.

Methods and Results. The numerical experiment on modeling the Marmara Sea circulation and evaluating its energy characteristics on the example of 2008 was carried out based on the eddyresolving nonlinear hydrodynamic model of Marine Hydrophysical Institute, RAS. The horizontal resolution of the model was $1.22 \times 0.83 \mathrm{~km}, 18$ horizons were used over vertical and the time step was $0.5 \mathrm{~min}$. Temperature, salinity and water discharge through the Bosporus and the Dardanelles were preset according to the available measurement data. The applied fields of atmospheric forcing were obtained from the calculation by the regional atmospheric model MM5. The volume-integrated and year-averaged contributions of the terms in the equations of the kinetic and potential energy budgets were analyzed. The basic factors of change in the Marmara Sea kinetic energy consisted in the buoyancy force action, wind, and vertical and horizontal mixing. Having been analyzed, the volume-average summands in the equation of rate of the kinetic energy change have shown that the wind-induced energy influx was compensated mainly by vertical friction, and the buoyancy force action - by horizontal friction. On the average, in course of a year the potential energy changed mainly due to its horizontal transport conditioned by the effect of the currents located in front of the straits, vertical diffusion and the buoyancy force impact. The results of analysis of the energy transitions permitted to reveal that in the upper sea layer, the mesoscale vortices were formed directly under the wind influence and as a result of the currents' baroclinic instability. Generation of the submesoscale vortices in the coastal regions was affected predominantly by the processes of baroclinic instability. In the region near the Bosporus, increase of the horizontal gradients in the density field and, consequently, intensification of dynamic processes are the results of inflow of the Black Sea waters with lower density.

Conclusions. Study of the energy characteristics of the Marmara Sea water circulation permitted to conclude that baroclinic instability and wind are two of the basic sources of eddy formation in this basin.

Keywords: numerical hydrodynamic model, Marmara Sea, kinetic energy, potential energy, cyclone, anticyclone, baroclinic instability.

Acknowledgments: the investigation is carried out within the framework of the state task on theme No. 0827-2018-0003 "Fundamental studies of oceanological processes determining state and evolution of marine environment under the influence of natural and anthropogenic factors based on observation and modeling methods".

For citation: Demyshev, S.G., Dovgaya, S.V. and Shokurov, M.V., 2019. Energy Characteristics of the Marmara Sea Water Circulation in 2008. Physical Oceanography, [e-journal] 26(4), pp. 275-287. doi:10.22449/1573-160X-2019-4-275-287

DOI: $10.22449 / 1573-160 \mathrm{X}-2019-4-275-287$

(C) 2019, S. G. Demyshev, S. V. Dovgaya, M. V. Shokurov

(C) 2019, Physical Oceanography

\section{Introduction}

Numerical modeling of the Marmara Sea circulation is one of the reconstruction components of the Mediterranean region thermo-hydrodynamic characteristics. The works on the Marmara basin circulation modeling are not numerous. General regularities of the water vertical distribution in this basin PHYSICAL OCEANOGRAPHY VOL. 26 ISS. 4 (2019) 
obtained using a simplified box model are given in [1]. In [2], based on the use of numerical nonlinear three-dimensional MHI model with high spatial resolution, the jet character of $S$-shaped current in the sea upper layer and the periodic manifestation of a cyclonic vortex near the northern boundary of the sea are determined. The formation of water circulation features under effect of atmospheric fluxes of heat, precipitation and evaporation is studied in [3]. In [4], the circulation features in September - December 2008 and February - March 2009 were simulated applying the numerical model ROMS. It is shown that wind and exchange through the straits affect the pycnocline displacement in different parts of the basin. Numerical modeling of water dynamics in the system of Turkish straits, including the Bosphorus Strait, the Marmara Sea and the Dardanelles Strait, using an unstructured grid and presetting the real atmospheric disturbance in 2009-2013 period is presented in [5], where possible mechanisms for blocking water flows from the Bosphorus Strait are indicated. The structure of hydrophysical fields of the Marmara Sea waters for September and December 2013, using an example of an algorithm for solving three-dimensional equations of ocean hydrodynamics without approximating hydrostatics and simplifying Coriolis acceleration, is given in [6]. It shows the proximity of the sea hydrophysical fields calculated in hydrostatic and non-hydrostatic dynamics modes. Some differences are observed on the bottom slopes, where the intensity of the currents increases. The question of which mechanism is predominant in the formation of the obtained features of the Marmara Sea water circulation remains open. The main factors that determine the dynamics in the basin are atmospheric effects and the exchange of mass, heat, salt and energy through the straits. In order to assess their contribution, it is advisable to use the energy method, which consists in calculating and analyzing the budget of kinetic (KE) and potential (PE) energies.

For the accuracy of calculating the energy budget, it is necessary that the discrete equations of $\mathrm{KE}$ and $\mathrm{PE}$ variation rate correspond to the finitedifference equations of the numerical dynamics model. Such equations were obtained in [7], on their basis an analysis of the Black Sea water climatic circulation was carried out and energy cycles in the areas with the greatest variability of currents were described. Taking into account real atmospheric effect, in [8] the intra-annual variability of temperature, salinity and current velocity fields in the Black Sea was studied on the basis of energy analysis. The example of 2006 shows that the determining factors for different seasons were the wind effect, the buoyancy force work and vertical turbulent exchange. In winter, the wind effect was decisive, in spring and summer - buoyancy force and vertical turbulent mixing.

In this paper the analysis of the Marmara Sea energy is carried out using a similar methodology [8] and on its basis the causes that determine the features of sea circulation in 2008 were found.

\section{Statement of the problem and parameters}

The model equations used are presented in detail in [3]. The model resolution along $x$ axis is $1.22 \mathrm{~km}$, along the $y$ axis $-0.83 \mathrm{~km}$. The selection of high horizontal resolution provided the simulation of submesoscale features of currents, which can make a significant contribution to the sea circulation variability. Vertical horizons 
$2.5 ; 5 ; 10 ; 15 ; 20 ; 25 ; 30 ; 40 ; 50 ; 62.5 ; 75 ; 100 ; 150 ; 300 ; 500 ; 700 ; 900 ; 1100 \mathrm{~m}$, time step is $0.5 \mathrm{~min}$. In the Bosporus and Dardanelles the current velocities were calculated according to the discharges presented in $[1,3]$ : in the Bosphorus upper layer $(0-20 \mathrm{~m})-650 \mathrm{~km}^{3} /$ year, in the lower layer $(20-100 \mathrm{~m})-350 \mathrm{~km}^{3} /$ year; in the upper $(0-20 \mathrm{~m})$ and lower $(20-75 \mathrm{~m})$ layers of the Dardanelles - 830 and $530 \mathrm{~km}^{3} /$ year, respectively. The temperature of water getting from the Bosphorus Strait varied in depth and over the time within $8-23.5^{\circ} \mathrm{C}$ range, salinity - within 21-30\% range in depth [9]. The waters entering in the Marmara Sea through the Dardanelles Strait had a constant temperature of $14.6^{\circ} \mathrm{C}$, while the salinity changed with depth within 34.5-38.68\% range [10-12].

The processes of turbulent momentum exchange and turbulent diffusion along the vertical were parameterized using the Pacanowski - Philander approximation [13]. The values of corresponding parameters [3] in this representation were obtained on the basis of numerical experiments in which the results of calculations were compared with the known features of location of the interface between two water masses of the basin. The coefficients of turbulent viscosity and turbulent horizontal diffusion took, respectively, the following values: $v_{H}=5 \cdot 10^{14} \mathrm{~cm}^{4} / \mathrm{s}$, $\kappa^{H}=5 \cdot 10^{14} \mathrm{~cm}^{4} / \mathrm{s}$.

The daily average fields of tangential wind stress, heat fluxes, precipitation and evaporation for 2008, which are preset as boundary conditions on the sea surface, are taken from the calculation according to the regional atmospheric model Fifth-Generation Penn State/NCAR Mesoscale Model version 3.7 (MM5) (http://www.ucar.edu/mm5/mm4/home.html).

At the bottom, the conditions of sticking and the absence of heat and salt fluxes were accepted for the velocity components. On the rigid lateral sides the normal velocity components were equal to zero and a slip condition for the other component was satisfied, as well as the condition for the absence of heat and salt fluxes through the solid boundary sections. In the straits on the water flows in (Upper Bosporus and Lower Dardanelles currents) the flux rates and values of temperature and salinity were preset, and in the water flows out (Lower Bosphorus and Upper Dardanelles currents) the velocities in the straits and the derivatives of temperature and salinity were equal to zero [3].

The initial fields for horizontal current velocities, salinity, temperature and level corresponded to August $28\left(6620^{\text {th }}\right.$ day of calculation); they were obtained in [2] in an experiment with the same parameters as in this work, but excluding atmospheric effects. The long integration period was due to the determination of currents in the lower sea layers. Calculation of hydrodynamic characteristics was carried out during the period from January 1 to December 31, 2008.

Detailed conclusion and analysis of the properties of $\mathrm{KE}$ and PE budget discrete equations are presented in [7,8]. We give a general view of the equations and expressions used for their components. Assuming that $\mathrm{KE}$ in the quasistatic approximation is expressed as $E=\rho_{0}\left(u^{2}+v^{2}\right) / 2$, we write down the equation of its budget in the symbolic representation as follows

$$
E_{t}+A d v(P+E)=B F W+F_{B f r}^{\tau}(E)-D_{i s s_{V e r}}(E)-D i s s_{H o r}(E) .
$$

In this case, the work of pressure forces and $\mathrm{KE}$ advection have the following form 


$$
A d v(P+E)=\left(u\left(g \zeta+E+P^{\prime}\right)\right)_{x}+\left(v\left(g \zeta+E+P^{\prime}\right)\right)_{y}+\left(w\left(g \zeta+E+P^{\prime}\right)\right)_{z} .
$$

Buoyancy force work, energy influx from the wind and KE dissipation due to internal vertical and horizontal friction are expressed respectively as follows [7]:

$$
\begin{gathered}
B F W=g \rho w, \\
F_{B f r}^{\tau}(E)=v_{V}\left(u u_{z}+v v_{z}\right)_{z}, \\
\operatorname{Diss}_{V e r}(E)=v_{V}\left(u_{z}^{2}+v_{z}^{2}\right), \\
\operatorname{Diss}_{H o r}(E)=v_{H}\left(\left(\nabla^{2} u\right)^{2}+\left(\nabla^{2} v\right)^{2}\right) .
\end{gathered}
$$

Volume integration (1) gives

$$
\begin{aligned}
& <E_{t}>_{V}+<A d v(E)>_{V}+<A d v(P)>_{V}=<B F W>_{V}+<\tau \rightarrow E>_{S}- \\
& -<\operatorname{Diss}_{\text {Ver }}(E)>_{V}-<\text { Diss }_{\text {Hor }}(E)>_{V} .
\end{aligned}
$$

For convenience of analysis, the separate term $\langle\tau \rightarrow E\rangle_{S}$ was selected in (7) for the influx from the wind, and the contribution from $F_{B f r}{ }^{\tau}(E)$ due to the boundary condition at the bottom was recorded in $\left\langle\operatorname{Diss}_{V e r}(E)\right\rangle_{V}$. The advective terms on the left side of equation (7) are not equal to zero and depend, inter alia, on water exchange through the straits.

Considering that the potential energy is equal to $\Pi=-\mathrm{g} \rho \mathrm{z}$, its variation is represented as follows:

$$
\begin{aligned}
& \Pi_{t}+A d v(\Pi)=-B F W-\operatorname{Diff}_{\text {Hor }}(\Pi)+\operatorname{Diff}_{\text {Ver }}^{\text {Fluxes }}(\Pi)+\operatorname{Diff}_{\text {Ver }}^{\text {Bot-Sur }}(\Pi)- \\
& -\operatorname{Diff}_{\text {Ver }}^{k^{V}}(\Pi)-\text { Diff }_{\text {Ver }}^{\text {Add }}(\Pi),
\end{aligned}
$$

where $A d v(\Pi)$ is an advection of potential energy; Diff ${ }_{H o r}(\Pi)$ is $\mathrm{PE}$ variation determined by horizontal diffusion; Diff Ver $^{\text {Fluxes }}(\Pi)$ is PE variation due to buoyancy fluxes through the sea surface and its vertical internal diffusion; Diff Ver $_{\text {Bur }}^{\text {Su }}(\Pi)$ is PE variation due to the difference between the bottom and surface density; $\operatorname{Diff}_{V e r}^{k^{V}}(\Pi)$ is PE variation due to turbulent mixing in depth; Diff Ver $_{\text {Add }}(\Pi)$ is an additive introduced as a result of a nonlinear dependence of sea water density on temperature and salinity. The terms on the left and right sides of equation (8) are presented in the following form [7]:

$$
\begin{gathered}
\operatorname{Adv}(\Pi)=(u \Pi)_{x}+(v \Pi)_{y}+(w \Pi)_{z}, \\
\operatorname{Diff}_{\text {Hor }}(\Pi)=k^{H}\left(\nabla^{2} \Pi-g z Q^{H}\right), \\
\operatorname{Diff}_{\text {Ver }}^{\text {Fluxes }}(\Pi)=g\left(k^{V} z \rho_{z}\right)_{z}, \\
\operatorname{Diff}_{\text {Vor }}^{\text {Bot-Sur }}(\Pi)=g\left(k^{V} \rho\right)_{z},
\end{gathered}
$$




$$
\operatorname{Diff}_{\text {Ver }}^{k^{V}}(\Pi)=g z\left(k^{V}\right)_{z} \rho .
$$

In the formulas (2) - (6) and (9) - (13) the following notations [7] were introduced: $u, v, w$ are the components of the velocity vector directed along $x, y, z$ axes, respectively; $g$ is a free fall acceleration; $\zeta$ is free surface elevation; $\rho$ is a sea water density; $P^{\prime}=g \int_{0}^{z} \rho d \mu ; v_{V}$ is vertical turbulent viscosity coefficient; $k^{V}$ is vertical turbulent diffusion coefficient; $Q^{H}$ is an additional term determined by the nonlinearity of the equation of state.

As a result of equation (8) volume integrating, we obtain

$$
\begin{aligned}
& <\Pi_{t}>_{V}+<A d v(\Pi)>_{V}=-<B F W>_{V}-<\text { Diff }_{H o r}(\Pi)>_{V}+ \\
& +<\text { Diff }_{\text {Ver }}(\Pi)>_{V}+<\text { Fluxes }>_{S},
\end{aligned}
$$

where $\left\langle\text { Diff } f_{v e r}(\Pi)\right\rangle_{V}$ term includes the sum of the fourth, fifth and sixth integrated terms in the volume on the right side of equation (8) and internal vertical diffusion. For convenience of analysis, in (14) a separate term $\langle\text { Fluxes }\rangle_{S}$ was used to single out PE variation, which is due to the presence of buoyancy fluxes on the sea surface. In formulas (7) and (14) index $V$ indicates on the integration over the basin volume, and index $S$ indicates on the integration over its surface.

\section{Numerical experiment results}

The performed calculation made it possible to obtain three-dimensional fields of hydrodynamic and energy characteristics of the Marmara Sea water circulation for every day of 2008. In the above-considered equations of kinetic (7) and potential (14) energy budget, the terms were volume-integrated and year-averaged. A diagram representing the values and directions of energy fluxes transport is shown in Fig. 1. The angle brackets in the notation of terms from equations (7) and (14) are omitted hereinafter. A positive $B F W$ value indicates a transition from the available potential energy to kinetic one. Fig. 1 reveals the fact that KE increase on average over 2008 is mainly due to the work of the buoyancy force and the influx of energy from the wind. Their contribution was mainly compensated by horizontal and vertical energy dissipation. The work of pressure forces also increased the KE, but its effect is an order of magnitude smaller than the one of $B F W$ and $\tau \rightarrow E$. The advection of kinetic energy $(A d v(E))$ was affected insignificantly; its magnitude was two orders of magnitude smaller than the main sources of KE increase. On average, KE increase was observed over the year. The PE variation was mainly affected by the buoyancy force work, potential energy advection and vertical diffusion. An increase in PE in the system on average over the year occurred mainly due to its advection. This effect is due to the influx of fresher water from the Bosphorus. We note that the advective terms of KE and PE variation in the Bosporus and Dardanelles are also determined by the internal dynamics of the sea. Surface buoyancy fluxes and horizontal diffusion did not significantly affect the PE variation. The contribution to PE from a level change occurs through the contribution of the advective summand. Its representation contains $u$ and $v$, which, in their turn, are determined by $P=g \rho_{0} \zeta+P^{\prime}$. On average, PE increases over 2008. 


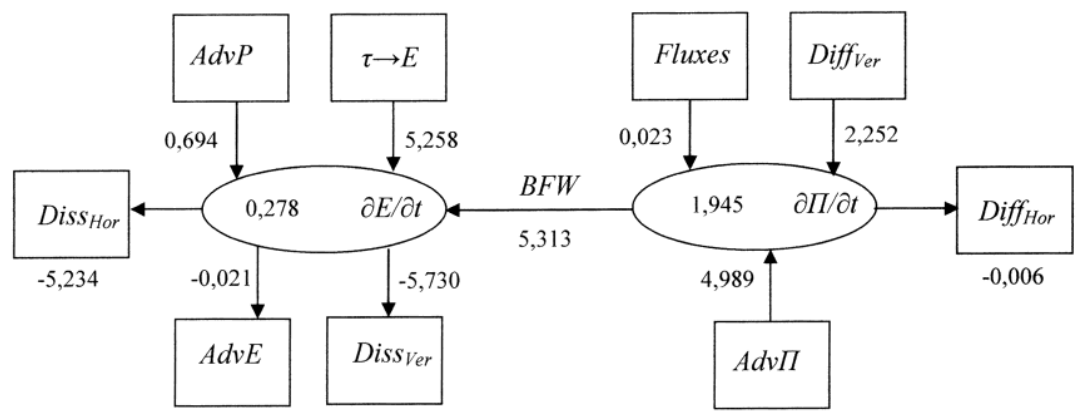

F i g. 1. Energy scheme of the summands' values averaged for $2008\left(\mathrm{~W} \cdot \mathrm{m}^{-3}\right)$ which, for the convenience of writing down, are increased by $10^{6}$ times in equations (7) and (14)

The flowchart in Fig. 1 represents an increase in total energy, which is due to the difference between the energy input and output. The effect of the considered atmospheric effect is described by two terms: $\tau \rightarrow E$ and Fluxes. The energy influx from the wind is almost completely compensated by vertical friction; the buoyancy fluxes on the surface are small. Therefore, it seems unobvious that taking into account the direct effect of the atmosphere automatically leads to an annual average increase in total energy.

We consider the distribution of energy fluxes in the hydrological seasons of the year (Fig. 2). For this, the values of the volume-integrated summands in equations (7) and (14) were averaged over these periods. Winter, spring, summer and autumn hydrological seasons assume three-month time intervals that begin on January 1, April 1, July 1 and October 1, respectively.

As it can be seen from Fig. 2, the main balance in the KE variation during all seasons was provided by four summands: buoyancy force work, horizontal energy dissipation, energy influx from the wind and vertical turbulent mixing. Comparing the signs and orders of these values, we can conclude that the buoyancy force work is mainly compensated by horizontal friction, the energy from the wind - by vertical friction. The work of advection forces was an order of magnitude smaller. For $\mathrm{PE}$ variation rate the main balance was kept between turbulent vertical mixing, buoyancy and PE advection. Horizontal diffusion and buoyancy fluxes on the sea surface turned out to be several orders of magnitude smaller.

In the winter period of 2008 the highest flux from PE to KE was observed (Fig. 2,a). The influx of wind energy was 2.9 times smaller than from $B F W$. The contribution from the buoyancy force in this period turned out to be 5.7 times greater than in spring (Fig. 2, b) and 9.2 times greater than compared to the summer period (Fig. 2, c). In summer, the greatest influx of energy from the wind and the smallest one as a result of the buoyancy force work were observed (Fig. 2, c). The variation rate of both KE and PE was negative in winter (Fig. 2,a) and it was positive in the rest of the year (Fig. 2, $b-d$ ). The highest PE growth was observed in summer, and its decrease occurred in winter (Fig. 2, a, c). Mentioned diagrams demonstrate an important role of potential energy advection in the average seasonal and, as a consequence, in the average annual balance. An analysis of the spatial distribution of this characteristic shows that its value mainly determines the water inflow through the Bosphorus. It follows that for adequate simulation of the Marmara Sea circulation it is necessary to take into account with high accuracy degree the impact of the waters getting from this strait. 

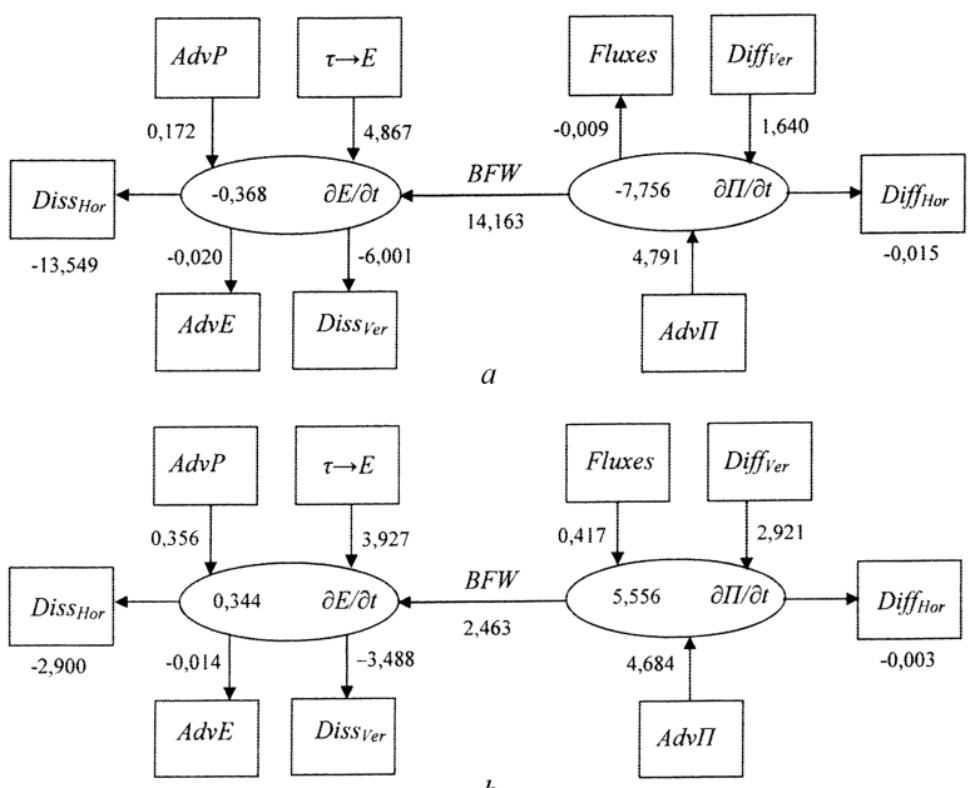

b
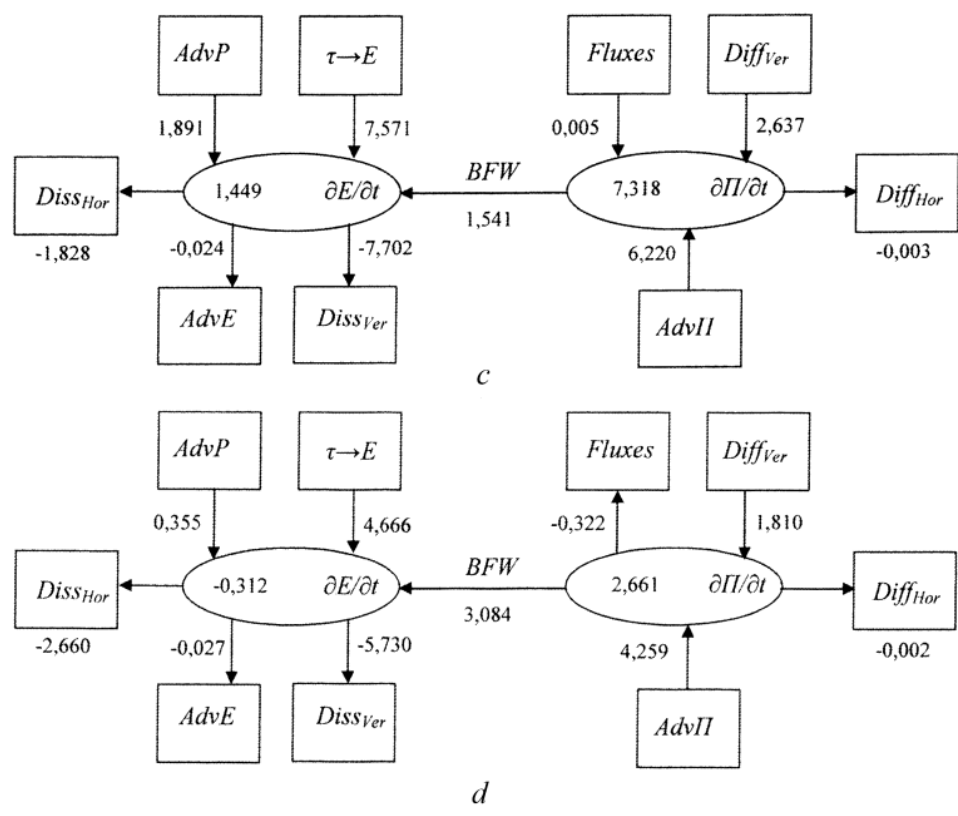

F i g. 2. Energy schemes of the summands' values averaged for the winter $(a)$, spring $(b)$, summer $(c)$ and autumn $(d)$ hydrological seasons, $2008,\left(\mathrm{~W} \cdot \mathrm{m}^{-3}\right)$ which, for the convenience of writing down, are increased by $10^{6}$ times in equations (7) and (14)

Now we are to analyze the intra-annual variability of the volume-integrated energy fluxes of the Marmara Sea basin. In Fig. 3 the graphs of temporal variation of those terms from equations (7) and (14), the contribution of which, taking into account the scheme in Fig. 1, is the most significant, are given. The greatest influx to KE took place from $B F W$ in February - April (curve 1 in Fig. 3, a). During this period, winter winds weakened (curve 2 in Fig. 3,a) and the contribution from the buoyancy force work prevailed. The energy input from the wind increased under 
effect of intense storm winds in the following periods of 2008: January 24-30, February 8-12, April 25 - May 1, July 12-14, July 30 - August 4, 22-24 and 27August 29, September 1-4, October 4-6, November 10-25. As a result, average summer energy influx from the wind is 1.5-2 times greater than in other seasons (Fig. 2). The behavior of curves 1 and 2 in Fig. 3, $a$ indicates that the energy influx from the wind was mainly compensated by vertical friction (curves 1 and 3 in Fig. 3,a). Diss $s_{V e r}(E)$ value is formed as a result of bottom friction and internal vertical friction effects. The dependence of vertical dissipation on the bottom friction is insignificant over the entire considered time interval. Therefore, the main role in this balance is played by internal friction. The volume-average work of the buoyancy force is compensated by horizontal dissipation (curves 2 and 4 in Fig. 3, $a, b$ ). Local time derivative of KE correlates with the energy influx from the wind (curves 2 and 5 in Fig. 3, $a, b$ ), which, in its turn, is in anti-phase with vertical dissipation (curves 2 and 3 in Fig. 3,a). This corresponds to the structure of energy fluxes in the diagram (Fig. 2,a). Therefore, despite the significant contribution of the buoyancy force work to the KE variation, on average over the space the main role here is played by the difference between the energy input from the wind and vertical friction.

The graphs reflecting the temporal variation of the most significant summands from the PE budget equation (14) are shown in Fig. 3, c. Comparing curves $1(B F W)$ and $5(\partial \Pi / \partial t)$, we can conclude that the main contribution to the $P E$ variation was made by the buoyancy force work - positive value $B F W$ decreased $\mathrm{PE}$ and increased KE. Throughout the year, $A d v(\Pi)$ value (curve 3 in Fig. 3, $c$ ) was approximately positive and constant, and therefore its positive contribution turned out to be in the annual average and seasonally average balances (diagrams in Fig. 1 and 2). Vertical diffusion (curve 2 in Fig. 3,c) was also non-negative throughout the year and thereby increased the contribution to the PE increase. The impact of buoyancy fluxes through the sea surface during the year varies insignificantly (curve 4 in Fig. 3,c). Thus, PE variation was determined by the difference between the sum of $A d v(\Pi), \operatorname{Diss}_{V e r}(E)$ and the buoyancy force work.

The performed analysis shows that if, on average, the contributions of some forces (such as buoyancy forces to the balance of kinetic energy variation and advection forces to potential energy variation) can be great, then locally the circulation features can be determined by other factors. As an example, we consider the formation of eddies in the coastal and deep-sea regions of the sea, as well as in the near-Bosporus area. Following the works [14, 15], we determine which eddies are considered mesoscale and submesoscale. Eddies, with the radii greater than the baroclinic radius of deformation of Rossby $\left(R_{\mathrm{d}}\right)$ and the Rossby number $\left(R_{0}\right)$ for them is much less than unity, are usually classified as mesoscale quasigeostrophic ones. Submesoscale ageostrophic eddies are those the radii of which are less than the radius $R_{\mathrm{d}}$, and $R_{0}$ is of the order of unity. As known,

$$
\begin{gathered}
R_{\mathrm{d}}=\frac{\sqrt{g H(\Delta \rho / \rho)}}{f}, \\
R_{0}=\frac{U}{R f},
\end{gathered}
$$

where $g$ is free fall acceleration; $H$ is depth; $f$ is Coriolis parameter; $U$ is orbital velocity of eddy; $R$ is a radius of eddy. For the Marmara Sea at $g=9.8 \mathrm{~m} / \mathrm{s}^{2}$, $H=25 \mathrm{~m}, \Delta \rho / \rho=10^{-2}, f=9.53 \cdot 10^{-5} 1 / \mathrm{s}$ we obtain $R_{\mathrm{d}}=17 \mathrm{~km}$. 

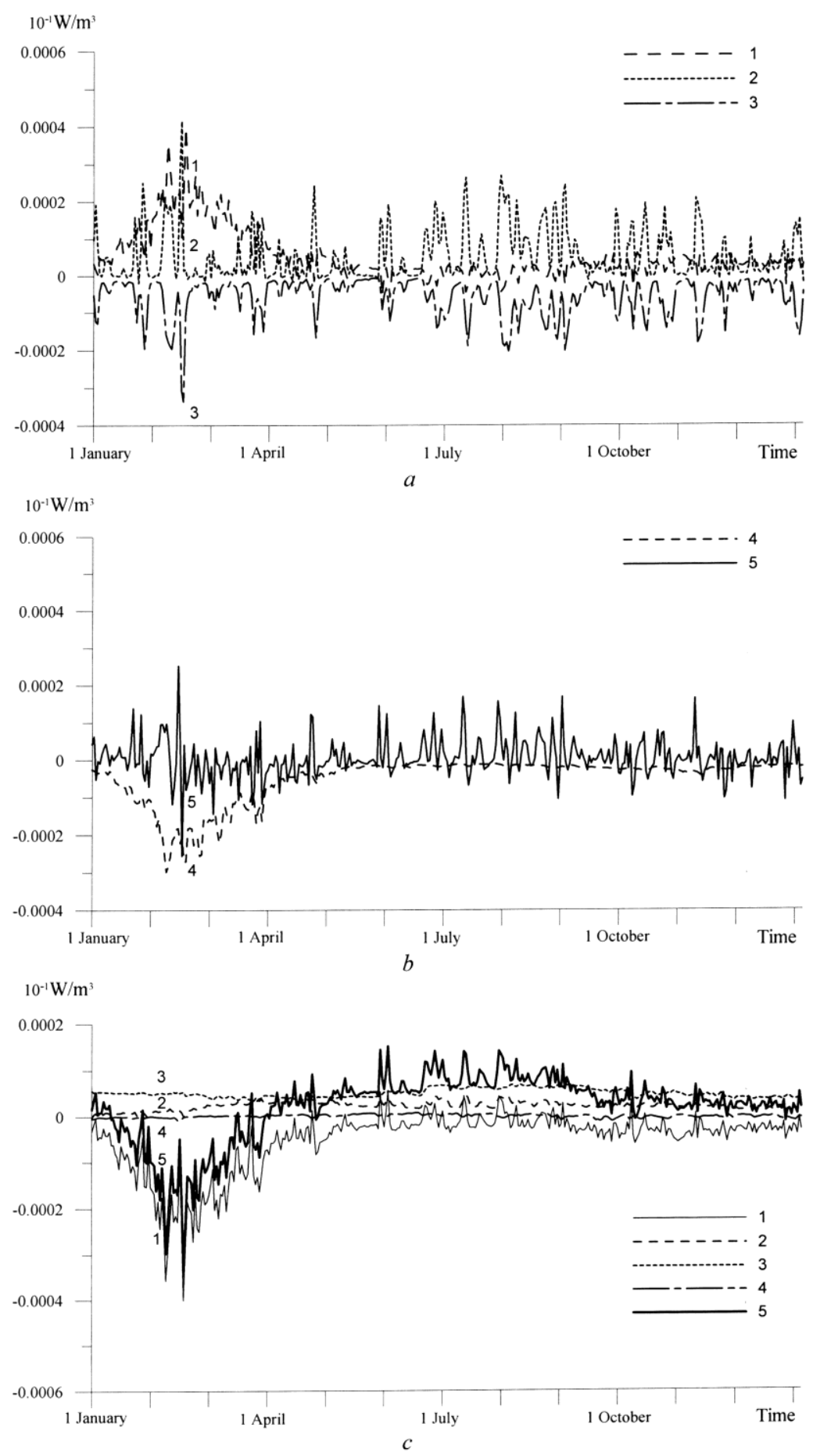

F i g. 3. Temporal variation of the volume-averaged summands in equation (7) $-a, b$ : curve $1-$ $B F W, 2-\tau \rightarrow E, 3-D_{i s s_{V e r}}(E), 4-D_{i s s_{H o r}}(E), 5-\partial E / \partial t$ and in equation (14) $-c$ : curve $1-$ ( $-B F W), 2-$ Diff $_{\text {Ver }}(E), 3-A d v(\Pi), 4-$ Fluxes, $5-\partial \Pi / \partial t$ 

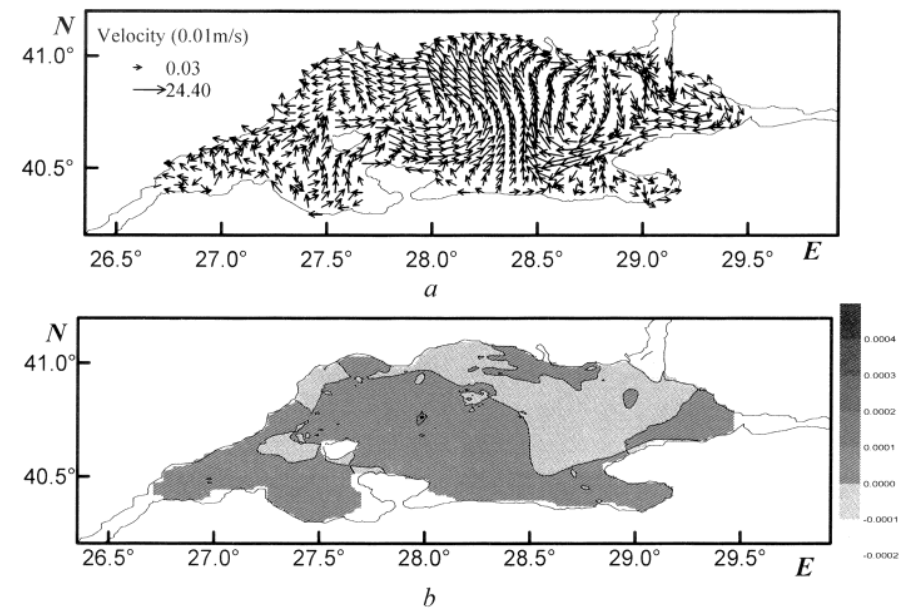

F i g. 4. Velocity field $-a$ and energy inflow from wind $\tau \rightarrow E\left(10^{-7} \mathrm{~W}\right.$, isolines $)-b$ on horizon $2.5 \mathrm{~m}$ on 20.03.2008

We are to analyze the mechanism of a cyclonic eddy formation in the western part of the sea (Fig. 4). In the period from March 16-20, a stable southwestern wind prevailed over the region. The area of positive values $\tau \rightarrow E$ in the central part of the sea corresponds to an extensive cyclonic formation with up to $40 \mathrm{~km}$ diameter and up to $0.12 \mathrm{~m} / \mathrm{s}$ orbital velocity. According to (16), $R_{0}=0.06$. Thus, this eddy with a radius greater than $R_{\mathrm{d}}$ and with $R_{0}<<1$ is a mesoscale one. Its penetration depth is $20 \mathrm{~m}$, life time is 8 days. During the formation of such a powerful cyclonic eddy, the quasi-stationary central anticyclone described in [1-3] moved to the eastern part of the sea (Fig. 4,a).
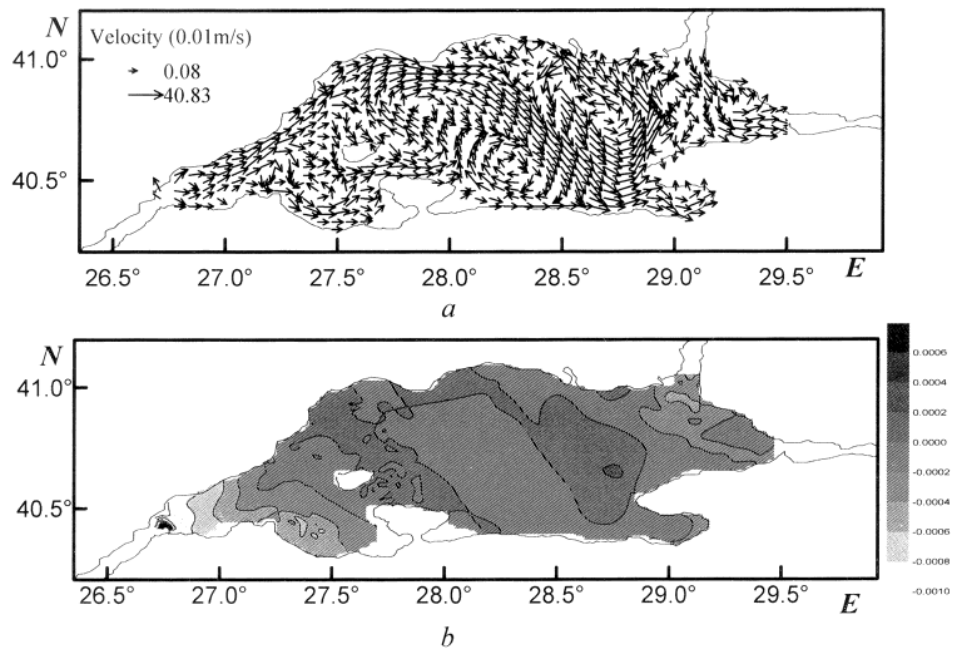

F i g. 5. Velocity field $-a$ and $B F W\left(10^{-7} \mathrm{~W}\right.$, isolines $)-b$ on horizon $2.5 \mathrm{~m}$ on 20.11 .2008

The effect of the buoyancy force work on the formation and development of mesoscale eddies is demonstrated by the following example (Fig. 5). In the eastern part of the basin (Fig. 5, a) a cyclone $\left(28.75^{\circ} \mathrm{E}, 40.63^{\circ} \mathrm{N}\right)$ with a diameter of about $50 \mathrm{~km}$, up to $0.24 \mathrm{~m} / \mathrm{s}$ orbital velocity to and $30 \mathrm{~m}$ penetration depth was formed. Its 
lifetime was 25 days. The Rossby number calculated by formula (16) for this cyclone at $U=0.24 \mathrm{~m} / \mathrm{s}, L=25 \mathrm{~km}, f=9.53 \cdot 10^{-5} 1 / \mathrm{s}$ will be equal to 0.1 . Therefore, this cyclonic eddy can be considered a mesoscale one. The location of the mesoscale eddy zone coincides with the region of increased positive values of the buoyancy force work, and, therefore, the formation of such a structure occurred as a result of the energy transfer from the available potential energy to kinetic one. Heavier Mediterranean waters, moving to the central region of the Marmara Sea as a result of inflow through the Dardanelles, cause an increase of the cross gradients in the density field and, as a result, an increase in the orbital velocities. Thus, it can be assumed that the baroclinic instability of the large-scale current causes the formation of this cyclonic eddy.
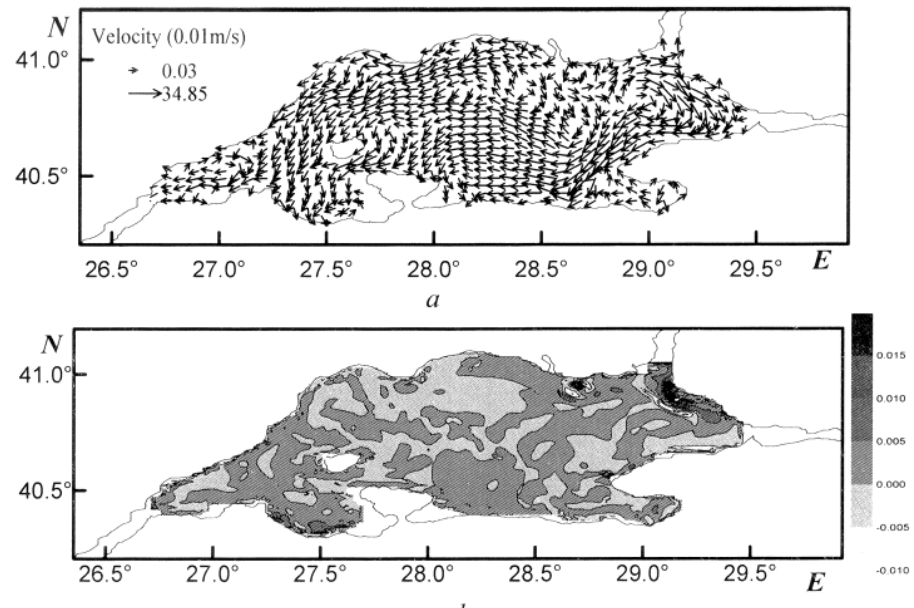

F i g. 6. Velocity field $-a$ and buoyancy force work $\left(10^{-7} \mathrm{~W}\right.$, isolines $)-b$ on horizon $10 \mathrm{~m}$ on 05.03 .2008

In the Marmara Sea baroclinic instability is also one of the possible mechanisms for the formation of coastal submesoscale eddies (Fig. 6). It can be seen that near the northeastern part of the coast $\left(28.65^{\circ} \mathrm{E}, 40.89^{\circ} \mathrm{N}\right)$ a cyclone with about $7 \mathrm{~km}$ diameter, up to $0.25 \mathrm{~m} / \mathrm{s}$ orbital velocity and up to $40 \mathrm{~m}$ depth (Fig. 6,a) was located. An analysis of the velocity field structure over the entire depth in this region showed that there is no evidence of shift instability. At the same time, on the corresponding map of the buoyancy force work distribution (Fig. $6, b$ ) at the location of this eddy the zones of maximum positive values $B F W$ alternate with the zones of high negative values $B F W$. Since the sign of the buoyancy force work is determined by the sign of the vertical velocity, then the spatial distribution of these zones depicted in Fig. 6, $b$ indicates on the existence of large horizontal gradients in the density field of this sea region. The availability of such a condition is an attribute of the formation of baroclinic instability, which results in a transition from available potential energy to kinetic one. For values of $U=0.25 \mathrm{~m} / \mathrm{s}, L=3.5 \mathrm{~km}, f=9.53 \cdot 10^{-5} 1 / \mathrm{s}$, for the presented eddy we have $R_{0}=0.75$ calculated from (16). The parameters of the certain eddy shown in Fig. 6, $a\left(R_{0}=0.75 \approx 1\right.$ and $\left.L=3.5 \mathrm{~km}<R_{\mathrm{d}}=17 \mathrm{~km}\right)$ satisfy the criterion for the submesoscale type of eddies, and the spatial distribution of the zones of buoyancy force work at its location indicates on the baroclinic instability of waters in this region. It can be also seen that at the same time, an anticyclone with $25 \mathrm{~km}$ 
diameter, $0.20 \mathrm{~m} / \mathrm{s}$ orbital velocity, up to $30 \mathrm{~m}$ penetration depth and a lifetime of 7 days was formed in the eastern part of the near-Bosporus region of the basin (Fig. 6, a). On the distribution map of the buoyancy force work (Fig. 6, b), extreme $B F W$ values due to the influx of fresher Black Sea waters are observed in the indicated region. Therefore, the formation of this eddy is associated with the process of energy transfer from available potential energy to kinetic one.

Since the computational grid size is 178 points along the abscissa axis and $104-$ along the ordinate axis and graphic visualization tools can not reflect the actual capabilities of the numerical grid, the vector fields shown in Fig. 4-6 are illustrative.

\section{Conclusion}

On the basis of MHI thermohydrodynamic model, taking into account real atmospheric effects of 2008, a numerical experiment was carried out to simulate the dynamic and energy characteristics of the Marmara Sea. Average annual and average seasonal balances of $\mathrm{KE}$ and $\mathrm{PE}$ are calculated.

On average, in 2008 total energy increase took place. Average annual KE variation is mainly due to the buoyancy force work and the energy influx from the wind, the contribution of which was compensated by dissipation of the energy in the horizontal and vertical directions. The PE variation was mainly affected by the buoyancy force work, PE advection and vertical diffusion. The increase in PE in the considered system on average over the year occurred mainly due to horizontal transport caused by the Bosphorus Strait impact.

The variation of average seasonal $\mathrm{KE}$ is due to the buoyancy force work, the horizontal energy dissipation, the energy influx from the wind and vertical turbulent mixing. An analysis of the volume-average summands in the equation of $\mathrm{KE}$ variation rate showed that the contribution from the buoyancy force work is compensated mainly by horizontal friction, and the energy influx from the wind is compensated by vertical friction. For the PE variation rate, the main balance is observed between turbulent vertical mixing, buoyancy force work and PE advection.

An analysis of the maps of the spatial distributions of the three-dimensional hydrodynamic and energy characteristics fields for the Marmara Sea water circulation on each day of the integration time allowed us to conclude that in the sea upper layer the mesoscale eddies can form both due to the effect of the wind and due to the baroclinic instability of the currents. The generation of the submesoscale vortices in the coastal regions is affected predominantly by the processes of the baroclinic instability. As a result of the inflow of waters with lesser density, an increase of the horizontal gradients in the density field and the development of eddy formation processes are observed in the near-Bosporus region.

\section{REFERENCES}

1. Beşiktepe, T.Ş., Sur, H.I., Özsoy, E., Latif, M.A., Oguz, T. and Ünlüata, Ü., 1994. The Circulation and Hydrography of the Marmara Sea. Progress in Oceanography, [e-journal] 34(4), pp. 285-334. https://doi.org/10.1016/0079-6611(94)90018-3

2. Demyshev, S.G., Dovgaya, S.V. and Ivanov, V.A., 2012. Numerical Modeling of the Influence of Exchange through the Bosporus and Dardanelles Straits on the Hydrophysical Fields of the Marmara Sea. Izvestiya, Atmospheric and Oceanic Physics, [e-journal] 48(4), pp. 418-426. doi: 10.1134/S0001433812040056

3. Demyshev, S.G., Dovgaya, S.V. and Shokurov, M.V., 2016. Effect of Heat Flow, Precipitation and Evaporatio on the Dynamics of the Marmara Sea Surface Water. Physical Oceanography, [e-journal] (3), pp. 3-13. doi:10.22449/1573-160X-2016-3-3-13 
4. Chiggiato, J., Jarosz, E., Book, J.W., Dykes, J., Torrisi, L., Poulain, P-M., Gerin, R., Horstmann, J. and Beşiktepe, Ş., 2012. Dynamics of the Circulation in the Sea of Marmara: Numerical Modeling Experiments and Observations from the Turkish Straits System Experiment. Ocean Dynamic, [e-journal] 62(1), pp. 139-159. doi:10.1007/s10236-011-0485-5

5. Aydogdu, A., Pinardi, N., Özsoy, E., Danabasoglu, G., Gürses, Ö. and Karspeck, A., 2018. Circulation of the Turkish Straits System under Interannual Atmospheric Forcing. Ocean Science, [e-journal] 14(5), pp. 999-1019. https://doi.org/10.5194/os-2018-7

6. Zalesny, V.B., Gusev, A.V. and Fomin, V.V., 2016. Numerical Model of Nonhydrostatic Ocean Dynamics Based on Methods of Artificial Compressibility and Multicomponent Splitting. Oceanology, [e-journal] 56(6), pp. 876-887. https://doi.org/10.1134/S0001437016050167

7. Demyshev, S.G., 2004. Energy of the Black Sea Climatic Circulation. Part I: Discrete Equations of the Time Rate of Change of Kinetic and Potential Energy. Russian Meteorology and Hydrology, (9), pp. 65-81.

8. Demyshev, S.G. and Dymova, O.A., 2016. Analyzing Intraannual Variations in the Energy Characteristics of Circulation in the Black Sea. Izvestiya, Atmospheric and Oceanic Physics, [e-journal] 52(4), pp. 386-393. https://doi.org/10.1134/S0001433816040046

9. Oguz, T., Özsoy, E., Latif, M.A., Sur, H.I. and Ünlüata, Ü., 1990. Modeling of Hydraulically Controlled Exchange Flow in the Bosphorus Strait. Journal of Physical Oceanography, [ejournal] 20(7), pp. 945-965. https://doi.org/10.1175/1520-0485(1990)020<0945:MOHCEF>2.0.CO;2

10. Zapevalov, A.S., 2005. Seasonal Variability of Vertical Distributions of Temperature and Salinity in the Sea of Marmara. Russian Meteorology and Hydrology, (2), pp. 78-84.

11. Beşiktepe, T.Ş., 2003. Density Currents in the Two-layer Flow: an Example of Dardanelles Outflow. Oceanologica Acta, [e-journal] 26(3), pp. 243-253. https://doi.org/10.1016/S03991784(03)00015-X

12. Beşiktepe, T.Ş., Özsoy, E. and Ünlüata, Ü., 1993. Filling of the Marmara Sea by the Dardanelles Lower Layer Inflow. Deep Sea Research Part I: Oceanographic Research Papers, [e-journal] 40(9), pp. 1815-1838. https://doi.org/10.1016/0967-0637(93)90034-Z

13. Pacanowski, R.C. and Philander, S.G.H., 1981. Parameterization of Vertical Mixing in Numerical Models of Tropical Oceans. Journal of Physical Oceanography, [e-journal] 11(11), pp. 1443-1451. https://doi.org/10.1175/1520-0485(1981)011<1443:POVMIN>2.0.CO;2

14. Kamenkovich, V.M., Koshlyakov, M.N. and Monin, A.S., 1987. [Synoptic Eddies in the Ocean]. Leningrad: Gidrometeoizdat, 509 p. (in Russian).

15. Thomas, L.N., Tandon, A. and Mahadevan, A., 2008. Submesoscale Processes and Dynamics. In: eds. M. W. Hecht, H. Hasumi, 2008. Ocean Modeling in an Eddying Regime. Washington D.C.: American Geophysical Union, pp. 17-38. doi:10.1029/177GM04

About the authors:

Sergey G. Demyshev - Chief Research Associate, Head of Wave Theory Department, Marine Hydrophysical Institute of RAS (2 Kapitanskaya Str., Sevastopol, 299011, Russian Federation), Dr.Sci. (Phys.-Math.), ORCID ID: 0000-0002-5405-2282, demyshev@ gmail.ru

Svetlana V. Dovgaya - Junior Research Associate, Marine Hydrophysical Institute of RAS (2 Kapitanskaya Str., Sevastopol, 299011, Russian Federation), ORCID ID: 0000-0003-3122-5053, dovgayasvetlana0309@yandex.ru

Mikhail V. Shokurov - Leading Research Associate, Marine Hydrophysical Institute of RAS (2 Kapitanskaya Str., Sevastopol, 299011, Russian Federation), Dr.Sci. (Phys.-Math.), ORCID ID: 0000-0003-1595-8281, shokurov.m@gmail.com

Contribution of the co-authors:

Sergey G. Demyshev - statement of the problem, analysis of the results

Svetlana V. Dovgaya - preparation of the model data, carring out numerical experiments, analysis of the results, preparation of the graphic materials and the paper text

Mihail V. Shokurov - preparation of the data of the atmospheric forcing

All the authors have read and approved the final manuscript.

The authors declare that they have no conflict of interest. 